International Journal of Agriculture, Environment and Bioresearch

Vol. 06, No. 03; 2021

ISSN: $2456-8643$

\title{
RECOVERY OF SOLID WASTE IN ARZEKE MARKETS AND DEPOSIT IN PARAKOU
}

\author{
TCHAKPA Cyrille ${ }^{(1)(2)}$ \\ ${ }^{1}$ Laboratoire Pierre Pagney Climat, Eau, Ecosystème et Développement (LACEEDE) / FASHS / UAC \\ ${ }^{2}$ Ecole Nationale Supérieure des Biosciences et Biotechnologies Appliquées (ENSBBA)/UNSTIM / 041 BP 175 \\ Cotonou (Rép. Bénin) +22997160073
}

https://doi.org/10.35410/IJAEB.2021.5626

\begin{abstract}
The Arzêkè markets and Deposit of Parakou generate badly managed important strong garbage quantities. This research has for goal to analyze the fashions of management of the strong garbage of these markets in order to find the strategies of purification.

The adopted methodological approach is based on the collection of the data to knowledge: the quantitative data, the demographic data and the data on socioeconomic by 157 people respecting the criterias (to have a boutique within one the markets, to have a polluting product display in one these markets, to have at least a seniority of 5 years in one these markets). The gotten data have been dealt with the help of the descriptive statistics and the analysis of the results with the PEIR model. The results show that the Arzêkè markets and Deposit produce 5232 tons of strong garbage on average per year. This strong garbageis collected by the ZIMEX society that assigns to transport them to the final discharge in order to incinerate them. The bad management of these garbage entails environmental and sanitary impacts. Considering the economic value that the strong garbage represents, it is necessary to think about their valorization.
\end{abstract}

Keywords: Fashions of management; Walked; Strong garbage; Parakou; Benin.

\section{INTRODUCTION}

The management of household waste has experienced over the past two decades in countries of the south as well as those of the north, a complication with the accelerated growth of cities. (TINI, p 122, 2003). Garbage management is at the center of international debates, particularly that of Rio de Janeiro in 1992 and New York in 1997.

In Benin, even if the causes seem to be common to those in Africa, there is nonetheless the lack of organization which remains the main cause (BLALOGOE P. p 42, 2009). Benin is making numerous efforts to resolve the problem, without however achieving overall satisfactory results. The evacuation rate for all of Benin is $17 \%$ with $39 \%$ in urban areas and $3 \%$ in rural areas (DANSOU B, p 29, 2015).

Like other municipalities in Benin, the municipality of Parakou, through this working tool, shows its desire to set up an effective waste management system (CISE, 2008)

The commune of Parakou is a city with a special status and considered to be a very large commercial crossroads in northern Benin. This city has several markets including the Arzêkè and Dépôt markets, real places of waste production (ADEME, p 12, 2014). It is therefore important and vital in the context of sustainable environmental sanitation, to proceed with the recovery of 
this waste because it remains the only management system "producer" of environment integrating the various rationalities (SECK MA p 21 , 1999). This waste management allows these markets to get out of the unhealthy framework in which they vegetate and attracts users more.

The commune of Parakou is limited to the north by the commune of N'Dali, to the south, east and west by the commune of Tchaourou, With an average altitude of $350 \mathrm{~m}$, it is located between $9^{\circ} 15^{\prime}$ and $9^{\circ} 30$ 'North latitude and $2^{\circ} 20^{\prime}$ and $2^{\circ} 45$ 'East longitude (Figure 1).

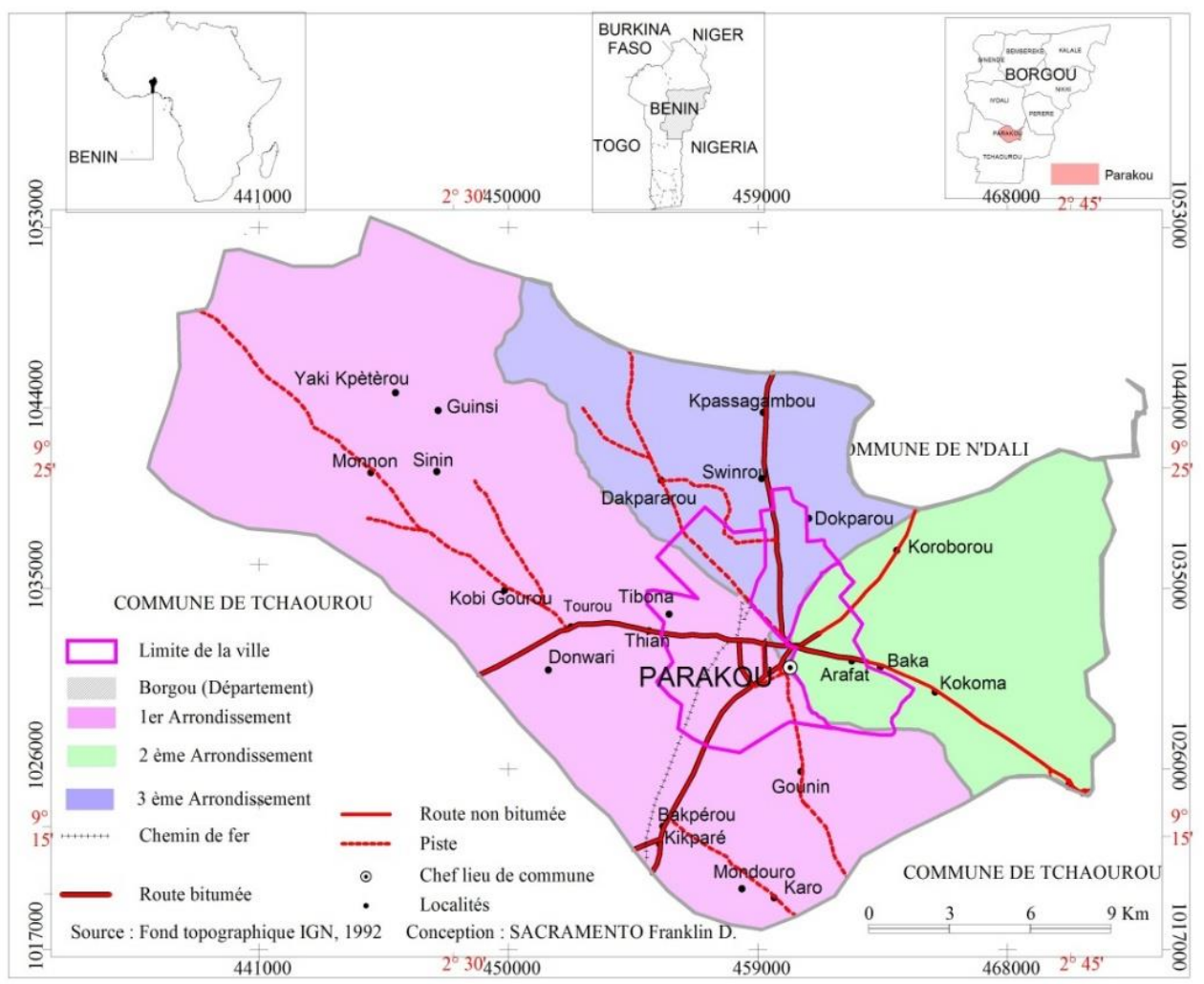

Figure 1: Geographical location of the city of Parakou

\section{METHODOLOGICAL APPROACH}

\subsection{Data used}

The data used are essentially qualitative and quantitative information collected during socioanthropological investigations. This information relates to the type of waste produced, their quantities, actors and methods of waste management and recovery strategies.

All the data thus obtained was 2.2. Methods used 
processed using the appropriate methods.

The choice of markets in which the surveys were carried out was made by giving priority to the two major markets of Parakou. They are identified on the basis of their international scope. As for the people surveyed, the choice was made on the basis of seniority in the markets, at least twenty (20) years. The interviewee is at least thirty (30) to 60 years old and is involved in the production of waste. A total of 157 people (100 sellers at the Arzêkè market and 57 sellers at the Dépôt market) were surveyed as part of this study.

Individual interviews and group discussion sessions were carried out using the questionnaires and the interview guide, respectively, to collect information from the resource persons. The KAP (Knowledge, Attitudes, Practices) approach is used to collect information relating to the problems related to the pre-collection, collection, sorting and preparation of the compost and to understand the perceptions and knowledge of the merchants. Direct observations in the field made it possible to better identify valuation strategies. All of this work has produced the following results.

\section{RESULTS}

\subsection{Economic activities within the Arzèkè and Dépôt markets}

The economy of the municipality of Parakou is essentially based on an industrial fabric making the city an industrial hub for the development of large aircraft transport activities, a predominant informal sector, a booming banking sector with the presence of the main banks of Benin, a flourishing commercial sector, a developed artisanal sector. The activities which occupy the populations of the Arzèkè and Dépôt markets are essentially commerce. Indeed, the Arzêkè and Dépôt markets attract a large number of users per day, i.e. 1720 for Arzêkè and 700 for Dépôt (SGMP, 2016) (Plate 1

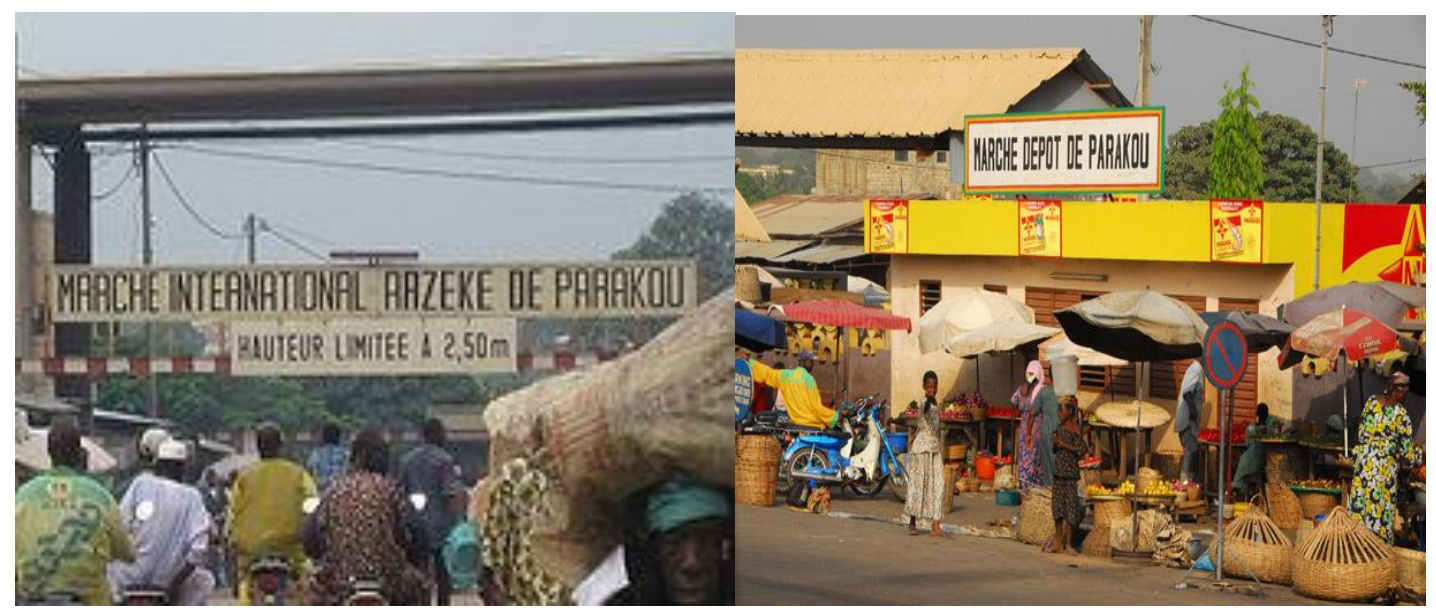

Plate 1: Partial view of the Arzêkè (a) and Dépôt (b) markets 
Shooting: TCHAKPA, March 2018

Plate 1 shows the facade of the Arzêkè and Dépôt markets. These markets receive several kinds of products such as cereals, tubers, market garden products and manufactured products. These different products generate different types of waste.

\subsection{Type of waste, their quantities and collection}

The type of waste produced by these markets is similar to that of households, namely: organic materials, bags, paper-cardboard, used plastics are part of this intermediate category between "Biodegradable and non-biodegradable".

Biodegradable waste accounts for $61.57 \%$ of market waste, it mainly consists of rotten fruits and vegetables and various fruit pits, seeds, slices and peelings, remains of food products, remains of tubers and other plant and animal matter) and of dry matter. (dead leaves, branches, flowers and wood debris). Non-biodegradable waste (38.43\%) consists of $10.02 \%$ of plastics; $7.49 \%$ cardboard and paper; $6.16 \%$ fines; $5.38 \%$ crab shells, shells and pearls; $3.78 \%$ metals; $2.64 \%$ glasses; $2.08 \%$ textiles and foam debris; $0.87 \%$ footwear and leathers.

The amount of solid waste varies depending on the market. In Arzêkè the production of waste varies between 38 and $52 \mathrm{~m} 3$ with an average of $45 \mathrm{~m} 3 / \mathrm{d}$ of collection. The truck passes twice a week to collect the rubbish from the transitory dumps of the Arzèkè market. The average waste produced in Arzèkè is $45 \mathrm{~m} 3$ per day of collection, the daily production is $15 \mathrm{~m} 3$, the weekly one is estimated at $90 \mathrm{~m} 3$. Its monthly production is $360 \mathrm{~m} 3$ and the annual production is 4,320 tonnes of waste. In the Depot market, the garbage collection truck passes twice a month and for each collection operation, it collects $38 \mathrm{~m} 3$. The market produces $3.16 \mathrm{~m} 3$ per day and $19 \mathrm{~m} 3$ of waste per week. Its production per month is $76 \mathrm{~m} 3$ and that generated per year is 912 tonnes (Table I).

Table I: Quantity of waste produced per day, week, month and year

\begin{tabular}{|l|c|c|c|c|}
\hline Markets & P / day (ton) & $\mathbf{P} /$ week (ton) & $\mathbf{P} /$ month (ton) & $\mathbf{P} /$ year (ton) \\
\hline Arzêkè & 15 & 90 & 360 & 4320 \\
\hline Deposit & 3.16 & 19 & 76 & 912 \\
\hline
\end{tabular}

Source: Field survey, March 2018

Table II shows that the Arzêkè market produces more waste than the Depot market. The Depot market is a small market compared to the Arzêkè market, it drains fewer users, thus producing a small amount of waste. The final Okédama landfill receives all the waste produced by the two markets (Photo 1). 


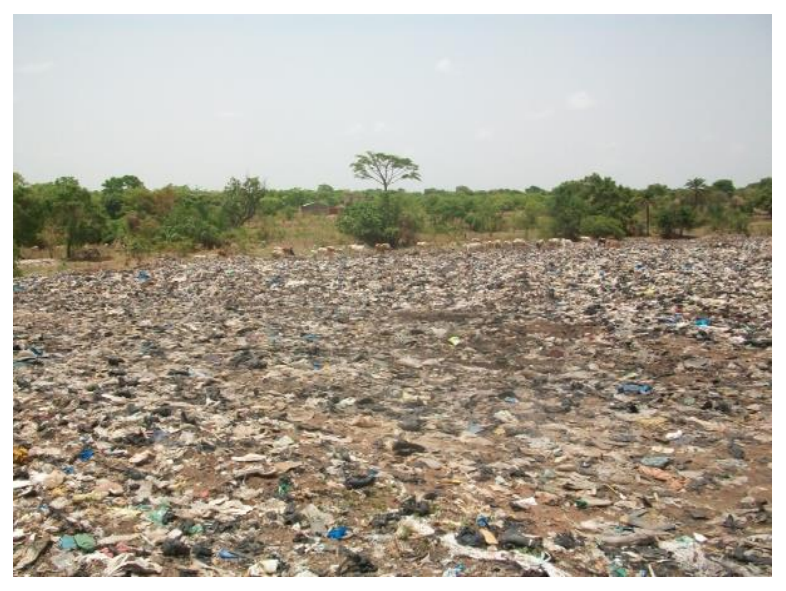

Photo 2: Final discharge from OKédama

Shooting: SOSSOU, March 2016

Photo 2 shows Okédama's final landfill in Parakou 1st arrondissement. After the waste is collected in the Arzêkè and Dépôt markets, it is transported to the final Okédama landfill in the 1 st arrondissement to be burned.

\subsection{Waste recovery strategy from the Arzêkè and Depot markets}

Pre-collection, collection, transport, treatment and recovery constitute the solid waste management methods in the city of Parakou. Among these modes, the one that appears more appropriate is recovery because it consists of giving life back to waste, creating outlets and being economically profitable. In Parakou, good waste management requires the contribution of all the inhabitants of the city in general and especially those of the Arzêkè and Dépôt markets.To this end, it is imperative to use IEC strategies (Information Education and Communication). It is important to emphasize that the said markets do not have a valuation system despite the presence of certain structures that take care of the cleanliness of the living environments of the users of these markets and of the neighboring populations. To do this, the option of recovering solid waste from these markets is essential for the city of Parakou and its surroundings. This recovery is twofold: material recovery and energy recovery.

\subsubsection{Material recovery}

Material recovery is the most practiced. This is organized into several sectors (Figure 1) 


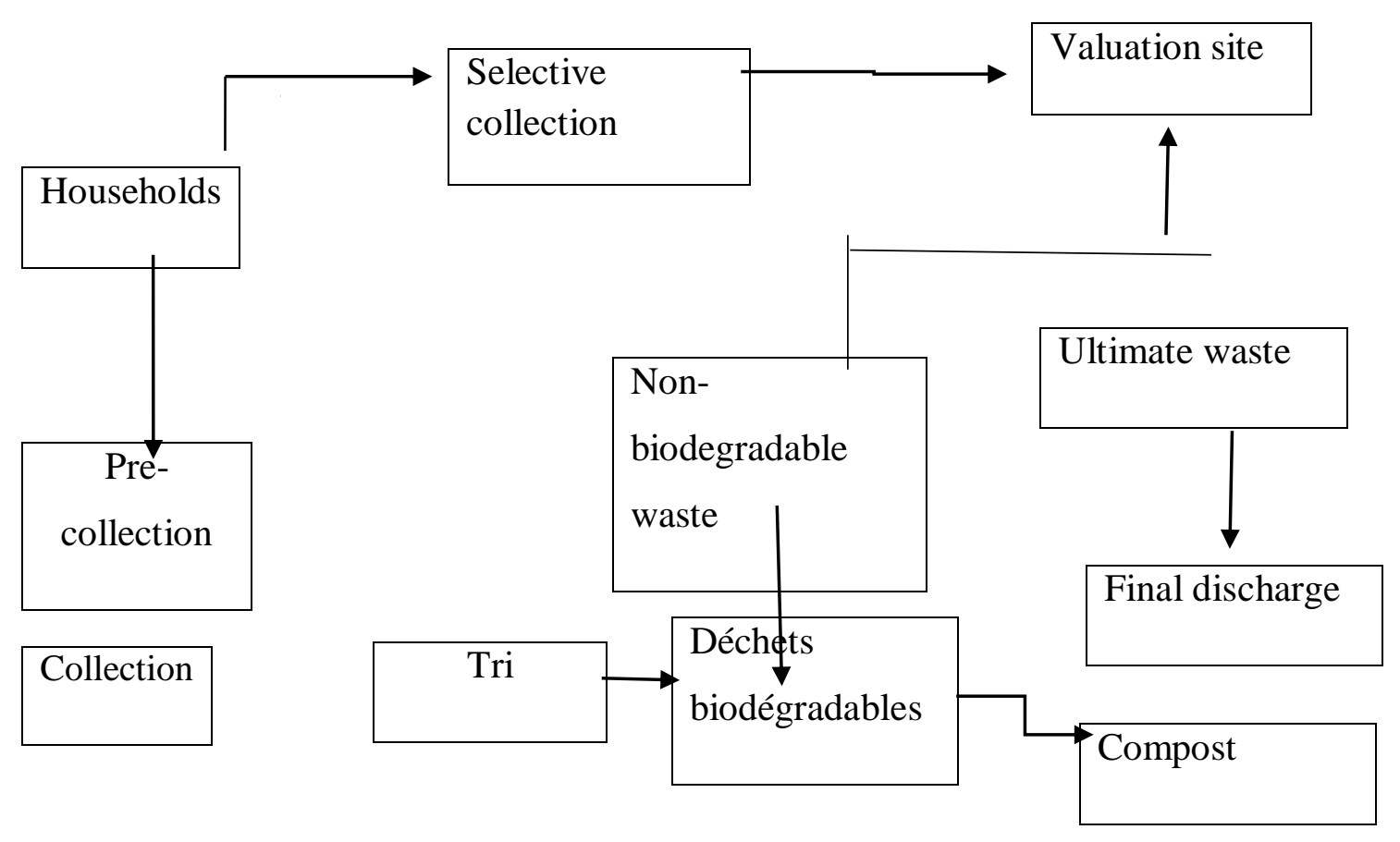

Figure 2: Household solid waste management system

\section{Source: (DCAM BETHESDA, 2011)}

Households are sensitized to subscribe to the elimination of all kinds of waste; thanks to the intervention of pre-collectors. At this stage, the pre-collectors equipped with carts go from house to house, to collect the garbage produced by these households and proceed to the trash.

The second step is collection, which consists of transporting the pre-collected waste by trucks and deposited in a specific and identified location to the sorting and treatment site.

The third step is to sort the waste once at the treatment site using a vibratory sieve which aims to extract biodegradable and non-biodegradable waste. Each fraction is then weighed and the percentage of the different calculated components.

Biodegradable waste $61.57 \%$ consists of rotten fruits and vegetables, animal droppings, straws, leftover meals, food products, and tubers). They are used in the preparation of compost, an organic product is that is to say natural. It consists of treating fermentable organic waste to produce a solid residue, rich in humus, similar to potting soil: the compost contains trace elements (NPK). The collected biodegradable waste undergoes five stages for the manufacture of compost. These stages are: sorting, separation, constitution of biodegradable piles (windrows 1 to 2 meters high), fermentation, maturation and then calibration. This is an aerobic method of making compost. The compost produced serves as an organic soil amendment and allows the latter to regain their fertility: it is an organic fertilizer (TCHAKPA C. 2011, p. 38). 
Vol. 06, No. 03; 2021

ISSN: $2456-8643$

Composting is often considered very expensive because it requires large means. But these means are recoverable with profits. Ultimately, those who want to compost must be trained so that they can make it for themselves.

It should be noted that biodegradable and non-biodegradable waste comes from certain materials used for personal purposes, it is necessary to integrate them into the recovery cycle because they constitute a great source of savings. This waste (plastics, scrap metal and others) is transformed into refined and reusable products either in their initial form or in any other product, for example: granules, press paper, pots, briquettes, garbage cans, electrical ducts, etc.

Ultimate waste is intended for final landfill for sanitary landfill. Table I shows the recovery of non-biodegradable waste after recycling.

Table II: Recovery of non-biodegradable waste

\begin{tabular}{|l|l|}
\hline \multicolumn{1}{|c|}{ Recycled waste } & \multicolumn{1}{|c|}{ Products obtained after recovery } \\
\hline Sachets & -Bags \\
& -Plastic sculpture \\
& -Hat \\
\hline Tins & -Lampion \\
& -Sieve \\
& -Rapper \\
\hline Polyethylene plastics & - buckets \\
& -Current ducts \\
& -Plastic cup \\
\hline Scrap & - Iron gate \\
& -Iron chairs \\
& -Wheel and rakes \\
\hline Paper and cardboard & -Coal \\
& -Notebooks \\
& - Briquettes \\
\hline
\end{tabular}


International Journal of Agriculture, Environment and Bioresearch

Vol. 06, No. 03; 2021

ISSN: $2456-8643$

\begin{tabular}{|l|l|}
\hline Os & -Traditherapeutic use \\
\hline Glasses & - Roof tile manufacturing \\
& -Security of houses by broken bottles \\
& -Reuse of bottles for various purposes \\
\hline
\end{tabular}

Source: Field survey, March 2016

Non-biodegradable waste (plastics, scrap metal, bones, glass, paper-cardboard and other recoverable waste) are transformed into refined and reusable products either in their initial form or in any other products highlighted in Table I.

\subsubsection{Energy recovery}

It is possible to obtain energy not only from recognized conventional sources (coal, oil, hydroelectric dam) but also from waste. Among the production methods, there is anaerobic digestion which gives biogas, densification, pyrolysis, gasification

\section{Biogas}

The biogas produced during methane fermentation is a mixture of $\mathrm{CO} 2$ and $\mathrm{CH} 4$. The energy benefit of this anaerobic digestion depends on the production and composition of the biogas. According to analyzes carried out in France, biogas is composed of CH4, CO2, N2, O2, H2O, Aromatic (mg / m3), H2S, Organo-halogen (mg-m3); a landfill equipped with gas suction and a waste digester. The capture and recovery of landfill biogas can limit the environmental impact of the landfill in terms of toxic discharge. Biogas makes it possible to reduce the phenomenon of greenhouse gases and to replace the excessive use of coal, which remains a dangerous practice for the flora and for the user; thanks to biogas the conception of energy is possible. The composition of the gas is determined by burning processes, where the gas contained in gasometers is burned if it ignites there is biogas otherwise carbon dioxide dominates. Despite these many advantages, biogas is a flammable fuel when poorly controlled and can cause serious incidents.

\section{Densification}

Densification is the set of operations to obtain biomass in a compact form. It consists of transforming matter by the combined action of temperature and pressure. These are cleaning or sorting residues, crushing and drying. In fact, densification decreases the humidity of the residues. The calorific value per unit volume of the densified residues is very high. It is twice as large as that of charcoal.

\section{Incineration}

It is a relatively complex technology with heavy investments due to the importation of complementary liquid fuels. The cost of the operation and the loss of energy make industrial 
Vol. 06, No. 03; 2021

ISSN: $2456-8643$

incineration unprofitable. Incineration is a process used to recover energy in the form of heat or electricity. Garbage (dry matter) is incinerated in an oven at $100^{\circ} \mathrm{C}$ : the heat released will heat the water contained in a boiler. The water temperature is calibrated by a turbo-alternator which allows energy to be recovered in the form of water vapor or electricity

-Pyrolysis and gasification

Pyrolysis and gasification are two related methods of heat treatment where materials are heated to very high temperatures and with little oxygen. The process is typically carried out in a sealed vessel under high pressure. Converting materials into energy this method is more efficient than direct incineration, as more energy can be recovered and used.

Energy recovery from waste contributes to saving fossil fuels and limits greenhouse gas emissions.

Some materials are also recyclable: paper, glasses, bones, horns, aluminum and iron.

\section{DISCUSSION}

The markets produce several kinds of solid waste varying according to the type. Solid waste far from constituting a nuisance to the population can be recovered. These observations agree with the results of LORIEAU (2008), and KOLEDZI (2011) who made the same remarks in West Africa.For these authors, by improving waste management by collecting all the waste generated by city dwellers by recovering the recyclable part and through agronomic enhancement of the organic part, this should help improve urban cleanliness while providing economic added value to the establishment of conditions for sustainable development.

The recovery of solid urban waste is of great importance for efficient and sustainable management. For VERNIER (2007), this importance can be noted mainly at two levels:

-from an economic point of view, he notes first of all a financial saving insofar as the recovery makes it possible to give financial value to a used material. Second, recovery also saves raw materials (wood for paper) or energy savings (recycling glass or aluminum)

-from the overall waste treatment point of view we can hope for a qualitative improvement of the treatment (by separating the glass, we will avoid finding it inert in the refusal of incineration or composting) or simply quantitative (by recycling everything possible, the quantity of waste to be treated is reduced by more expensive processes).

In a country like Switzerland, which has the most efficient urban waste management system in the world, particular emphasis is placed on waste recovery. A study by the Federal Office for the Environment, Forests and Landscape (OFEFP) in Switzerland reveals that $48 \%$ of urban waste is recycled. According to this same study with 7.2 million inhabitants, Switzerland and the Principality of Lichtenstein produce 4.99 million tonnes of urban waste per year. $48 \%$ of this waste, representing 2.41 million tonnes, is recycled thanks to efficient selective collection of the various recoverable components. Thus, the recycling sector has established itself in Switzerland 
as an increasingly efficient means of treating urban waste, considerably reducing the proportion of incinerated or buried urban waste.

In France, waste recovery also occupies a preponderant place. According to VERNIER, in 2007, in France $71 \%$ of glass was recovered for reuse and recycling; 54\% of cardboard packaging is recovered and recycled; $15 \%$ of textiles for

reuse and recycling; $19 \%$ of plastic bottles are recovered for reuse or recycling; $100 \%$ of metallic steel packaging, and $27 \%$ of metallic aluminum packaging is also recovered and recycled. To recover this waste under the conditions required for recovery, almost the entire French population is now served by selective collection compared to only $20 \%$ in 1997.

It should be noted, however, that if in countries such as France and Switzerland, the organizational and technological level has made it possible to achieve a high selective collection and recovery rate, this is not the case in developing countries. like Benin.

In Benin, the work carried out by authors such as BLALOGOE (2009), and TCHAKPA (2011) reached almost identical conclusions. According to these authors, the solid household waste produced in the city of Cotonou can be used in agricultural production instead of the use of chemical fertilizers of mineral origin which further impoverish the soil. Considering the agronomic value of the solid household waste produced in the city of Cotonou, its use in production would not only solve the problem of waste disposal in the city but also restore the land. There are advantages to using compost.

\section{CONCLUSION}

Research on the recovery of solid waste in the Arzèkè and Dépôt de Parakou markets has provided very useful data and information on the quantity and type of waste to be recovered. The amount of waste produced in the two markets averages 5,232 tonnes per year. Two types of waste recovery emerge: material recovery and energy recovery.

Material recovery includes two phases: recovery of biodegradable waste into compost for organic soil improvement; and the recovery (recycling) of non-biodegradable waste into. refined and reusable products.

Energy recovery includes anaerobic digestion which gives biogas, densification, pyrolysis, gasification

It therefore appears that waste recovery is the only management system that produces the environment and integrates the various rationalities. And given the importance of the economy it generates, it is appropriate to promote the recovery of waste.

\section{REFERENCES}

ADEME (2014): Waste edition, $80 \mathrm{p}$.

AFRIQUE CONSEIL (2006): Monograph of the municipality of Parakou, $44 \mathrm{p}$. 
BERTOLINI Gérard: The garbage market, economy and management of household waste. Collection: Environment 1'Harmattan, Paris 260 p.

BLALOGOE Parfait, (2009): Issue of agricultural recovery of solid household waste from Cotonou. DEA thesis, UAC / FLASH, 99 p.

CAMPAN Florence, (2007): Treatment and management of household waste at the meeting: geographic approach. Geography. University of Reunion, French. 420 p.

CHITOU Lise (2003): Effects of different types of compost made from household refuse from Cotonou on the production of headed cabbage on raw mineral soil on the coast. End of training thesis, Abomey-calavi, UAC, EPAC, 87 p.

CISE (2008): Waste management plan for the municipality of Parakou, $54 \mathrm{p}$.

DANSOU Brice, (2015): Waste management in the municipality of Pobè. DEA thesis, UAC / FLASH, 84p.

GBEDO, V. (2002): Study of endogenous practices for the recovery of solid household waste in Cotonou. DEA thesis, Abomey-calavi, UAC, EDP, 122 p.

LORIEAU Peter, (2008): Agricultural credit

KOLEDZI Edem Komi, (2011): Valorization of solid urban waste in Lomé. Doctoral thesis in chemistry and microbiology of water at the University of Limoges in joint supervision with Lomé $297 \mathrm{p}$.

SECK Mamadou Amidou, (1999); Composting waste recovery, organic amendment; RAC, Dakar, 43 pages

TCHAKPA Cyrille, (2011): Characterization and valuation by aerobic composting of solid household waste from the Fidjrossè district in Cotonou, University of Abomey Calavi (Benin) Master II, $56 \mathrm{p}$.

TINI Apollinaire, (2003): "Management of solid household waste in Niamey in Niger: Essay for a sustainable management strategy", thesis, Lyon, Institute of Applied Sciences of Lyon, Doctoral School Economics, Space and Behavior Modeling, 302p.

VERNIER Jacques, (2007): the environment Paperback published in the university presses of France $127 \mathrm{p}$.

VERNIERJacques, (2001): Importance of recovered waste in buildings equipped with the differentiated container system. Paris (France), similar pages 